\title{
Correlates of Surgical Treatment Type for Women with Noninvasive and Invasive Breast Cancer
}

\author{
STEVEN J. KATZ, M.D., M.P.H., ${ }^{1,2}$ PAULA M. LANTZ, Ph.D.,2 \\ and JUDITH K. ZEMENCUK, M.A. ${ }^{3}$
}

\begin{abstract}
There is concern that breast-conserving surgery is underused in some breast cancer patient subpopulations, including women with ductal carcinoma in situ (DCIS), an early-stage form of the disease. We conducted a population-based study to identify correlates of surgical treatment type and patient satisfaction, comparing women with DCIS and those with invasive disease. We used telephone interview and mailed survey of 183 women recently diagnosed with breast cancer (oversampling for women with DCIS), identified from the Metropolitan Detroit Cancer Surveillance System (response rate 71.2\%). Overall, 52.5\% of study subjects received a mastectomy $(48.9 \%, 45.8 \%$, and $73.5 \%$ of women with DCIS, local disease, and regional disease, respectively, $p<0.05$ ). One third of women did not perceive that they were given a choice between surgical types, and an additional one third of women received a surgeon recommendation, most of whom received the treatment recommended. Patient attitudes, such as concerns about the clinical benefits and risks of specific surgery options, were important correlates of treatment choice but did not vary by stage of disease. Knowledge about differences in clinical benefits and risks between surgery options was low. Finally, satisfaction with the decision-making process was significantly lower in women who did not perceive a choice between surgery options. Correlates of breast cancer surgery type appeared to be similar for women with DCIS and invasive breast cancer, with surgeons playing a dominant role in the process. Results also suggested that the decision-making process may be as important for patient satisfaction as the treatment chosen.
\end{abstract}

\section{INTRODUCTION}

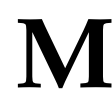
ANY PATIENT ADVOCACY GROUPS and clinical experts promote the use of breast-conserving surgery (BCS) for appropriate patients with breast cancer because, compared with mastec- tomy, lumpectomy with radiation therapy provides equal survival benefit, preserves the breast, and may yield less psychological sequelae and higher patient satisfaction. ${ }^{1-7}$ Despite widespread support of BCS, there is concern about its underuse based largely on evidence that the diffusion

Departments of ${ }^{1}$ Internal Medicine and ${ }^{2}$ Health Management and Policy, Consortium for Health Outcomes, Innovation and Cost-Effectiveness Studies (CHOICES), The University of Michigan, Ann Arbor, Michigan.

${ }^{3}$ Center for Practice Management and Outcomes Research, Ann Arbor VA Health Services Research \& Development Field Program, Ann Arbor, Michigan.

This study was supported by a grant from the National Cancer Institute (RO3CA75140) to the University of Michigan and program grant to the Detroit Karmanos Institute SEER Registry (N01-CN-65064). S.J.K. was also supported by a Robert Wood Johnson Generalist Faculty Scholars Award. This study was done in collaboration with the Metropolitan Detroit Cancer Surveillance System. We also acknowledge the support of the Center for Practice Management and Outcomes Research, Ann Arbor VA Health Services Research \& Development Field Program. 
of BCS has been slow and widely variable across geographic areas and patient subgroups. ${ }^{8,9}$ Lazovich et al. ${ }^{10}$ found that during 1995, the rate of BCS among stage I breast cancer patients ranged from $41 \%$ to $71 \%$ across Surveillance, Epidemiology and End Results (SEER) tumor registries. Additional studies have shown that the rate of BCS varies by provider, hospital characteristics, and patient attributes, such as age, ethnicity, and socioeconomic status. ${ }^{11-17}$

There is growing concern that BCS may be particularly underused for women with ductal carcinoma in situ (DCIS), which is a type of earlystage breast cancer where epithelial cells with cytological features similar to features of infiltrating carcinoma have proliferated within mammary ducts but have not yet invaded surrounding tissue. ${ }^{18}$ Since the advent of widespread mammography screening during the 1980s, the incidence of DCIS has greatly increased. In 1997, DCIS accounted for $17 \%$ of all breast cancer cases and almost one half of cases that were detected by mammography in the United States. ${ }^{19,20}$

Research has demonstrated that lumpectomy with radiation affords the same high survival rates as mastectomy for women with DCIS,, 21 although the role of radiotherapy in the treatment of patients with DCIS is still being debated. ${ }^{20}$ The recurrence rate for DCIS patients undergoing lumpectomy with radiation ranges from under $5 \%$ to over $15 \%$ in currently published studies, and many recurrences are invasive. ${ }^{20,22,23}$

Until recently, modified radical mastectomy remained the most common surgical procedure for DCIS, and marked geographic variations in treatment patterns continue to be observed nationally. ${ }^{24-27}$ Ernster et al. ${ }^{24}$ found that the proportion of women with DCIS receiving mastectomies in 1992 ranged from $29 \%$ in Connecticut to $58 \%$ in New Mexico. The fact that many women with DCIS receive mastectomies even though they ostensibly are optimal candidates for lumpectomy is viewed as further evidence that breast conservation is underused.

Although there have been several studies of surgical treatment type among women with invasive breast cancer, there is limited information about surgical choice for patients with DCIS. ${ }^{8,28-32}$ Most prior studies of the correlates of surgical treatment type among women with invasive disease were not population based but, instead, focused on small, convenient samples at large medical facilities. Thus, at present, there is a paucity of information regarding breast cancer surgical treatment decisions in populationbased samples of women, especially those with DCIS.

To address some of these important issues, we conducted a study of surgical treatment decisions in a sample of women identified through a population-based tumor registry, comparing women with DCIS with those with invasive disease. A main goal of our study was to test a methodology for collecting information on surgical treatment from a population-based sample of recently diagnosed breast cancer patients. Within this context, our primary study questions were: (1) Does the receipt of BCS vary by stage of breast cancer at diagnosis (DCIS versus invasive disease)? (2) What factors are important correlates of surgical treatment type for women, and does this differ by stage at diagnosis? (3) Does satisfaction with the treatment choice or with the decision process differ by type of procedure chosen or how the decision was made?

\section{MATERIALS AND METHODS}

\section{Study subjects and data collection}

The study population was a sample representative of all women diagnosed with primary DCIS or nonmetastatic invasive breast cancer in the three-county greater Detroit metropolitan area and reported prospectively to the Metropolitan Detroit Cancer Surveillance System (a SEER registry) during a 5-month period in 1998. Cases were identified using a rapid reporting mechanism that was capable of identifying and ascertaining the pathological stage of $80 \%$ of breast cancer cases within 4 months of initial diagnosis. (Ascertainment was not $100 \%$ because some of the smaller hospitals in this SEER catchment area do not participate in the early reporting program.) Criteria for inclusion in the study included being female and having a primary diagnosis of nonmetastatic breast cancer. Because anatomic staging information is not typically available in the first patient report to the SEER registry, we included both local (node negative) and regional stages of breast cancer in the invasive group. To achieve a balanced split between women with DCIS and those with invasive disease, we included all women with DCIS and a 15\% random sample of women with nonmetastatic invasive disease in the potentially eligible study popula- 
tion ( $n=340$ women over the 5-month study period).

The data collection protocol involved (1) mailed letters to the physicians of record for passive consent to contact patients, (2) telephone contact with potential study subjects to determine eligibility and which version of the survey to mail (based on perception of surgical treatment choice), and (3) implementation of the Dillman method $^{33}$ for survey research (i.e., mailing the survey/informed consent form/gift, a reminder postcard 2 weeks later, and then sending second and third surveys to nonresponders 4 and 8 weeks later). For 22 women (6.5\%), attending physicians refused to give consent to contact their patient, 29 women $(8.5 \%)$ were unavailable by telephone (most due to moving away or death), and 32 women $(9.4 \%)$ were determined ineligible during a telephone contact. This left 257 women confirmed as eligible for the mailed survey. Data from the surveys were linked to additional data from the SEER tumor registry, including pathological staging information.

\section{Survey content and variables}

The content of the surveys was developed based on a conceptual model of correlates of surgical treatment type for women with breast cancer, informed by several health behavior theories, including the Health Belief Model, Social Learning Theory, and the Behavioral Model of Health Services Utilization. ${ }^{34-36}$ At the center of our model are knowledge, attitudes, and preferences of patients, including knowledge and attitudes about (1) clinical benefits and risks of treatment, (2) barriers to treatment, and (3) preferences about body appearance and sexuality issues. External influences are also important correlates, especially the opinions and recommendations of surgeons. Clinical factors, such as tumor characteristics and stage at diagnosis, are important because they affect the probability of local recurrence of disease and perceptions about survival. Predisposing patient factors, such as age, ethnicity, and education, may be associated with underlying attitudes and preferences that influence patient's decisions about treatment. Finally, enabling patient factors, such as income or having a partner, may influence patient decision making because these factors are associated with access to certain services, such as radiation therapy.

Two versions of the questionnaire were ad- ministered based on whether or not a woman perceived that she was given a choice between the two surgical treatments (assessed at the time of the initial telephone contact). Women who perceived choice were given the full questionnaire, whereas women who did not perceive that they had a choice or options regarding surgery were given a shorter questionnaire that excluded items related to psychosocial correlates of procedure choice. The surveys were written at a sixth grade reading level.

The principal dependent variable under study-surgical treatment type-was ascertained in the survey by asking women if they had had a single mastectomy, double mastectomy, or lumpectomy (with each procedure described). Two other dependent variables related to patient satisfaction were included: satisfaction with the treatment decision made among women who perceived choice (using the six-item HolmesRovner et al. Satisfaction with Decision Scale) and satisfaction with the decision-making process among all women, which was measured with three individual items regarding satisfaction with perceived control or participation in the decision making (see Appendix for question formats). ${ }^{37,38}$ The responses to the Holmes-Rovner scale items were added and then collapsed into tertiles indicating increasing dissatisfaction with the treatment decision.

Independent variables pertaining to patient knowledge and attitudinal factors were adapted from sources in the published literature. For attitudinal factors, the phrase "When you were deciding between mastectomy and lumpectomy, how much was your decision influenced by whether the treatment you chose ..." was followed by a list of several items, using a 4-point Likert response scale ranging from strongly influenced to not influenced at all (see Appendix for preamble and question formats).

Additional independent variables included SEER stage (DCIS, local, regional), age at diagnosis (continuous), education (four levels), marital status (currently married versus other), and influence of the surgeon, which was assessed with several questions. First, we asked respondents if they perceived that they were given a choice between the two procedures. If respondents did not perceive that they were given a choice between procedures, influence of a surgeon was assumed. Second, women who perceived choice were asked if the surgeon had rec- 
ommended one procedure over another, and if yes, which procedure was recommended and how much their decision was influenced by their surgeon's recommendation.

\section{Analysis}

Frequency distributions and contingency table analyses were performed to assess the distribution of variable responses in the sample and to identify any unadjusted differences in the study population by stage and perceived choice (comparing women who perceived a surgical treatment choice with those who did not). Next, we examined which independent variables under study appeared to be important in women's choice of procedure (among women who perceived choice). We calculated the proportion of women who reported receiving a recommendation for a specific procedure from a surgeon, the proportion who reported being "greatly influenced" by the recommendation, and the proportion who had the recommended procedure.

Our analysis of women who perceived making a surgery decision also focused on which attitudinal factors were significantly associated with receipt of a specific surgical procedure. First, the proportion of women who reported that their decision was "greatly influenced" by a given attitudinal item was calculated. Next, logistic regression analysis was performed to identify individual attitudinal items associated with type of surgery received. The dependent variable was procedure type (mastectomy $=1$; lumpectomy $=$ $0)$. The independent variables included attitudinal variables (coded to 1 if a women reported being "greatly influenced" by the given attitudinal item) entered into separate models controlling for age, stage, education, and marital status. Odds ratios (OR) (and 95\% confidence intervals [CI]) were calculated to determine how much more or less likely the women who reported being influenced by each attitudinal factor were to receive a mastectomy.

We then examined level of knowledge about the risks and benefits of the different surgical options and whether there was an association between level of knowledge and the type of procedure performed. Finally, we examined associations between the satisfaction-dependent variables and selected independent variables. We first examined factors associated with satisfaction with the treatment decision (among those who perceived choice) by regressing the HolmesRovner scale on age, stage of disease, education, and surgical treatment chosen using ordinal logistic regression. We then examined associations among the three items indicating satisfaction with the surgical treatment decision-making process (among all respondents, excluding only those who reported a contraindication to BCS), using contingency table analysis to identify any significant associations between these satisfaction variables and whether or not the woman perceived choice and stage of disease at diagnosis.

\section{RESULTS}

\section{Survey response}

Of the 257 women who were deemed eligible and contacted by telephone, $42(16.3 \%)$ refused to participate during the initial telephone contact. Subsequently, 215 self-administered survey questionnaires were mailed to eligible women, of which 183 were completed and returned. Thus, the survey response rate was $71.2 \%$ (183 of 257) among women contacted by phone and determined to be eligible for the study, and $85.1 \%$ (183 of 215) among those who received a mailed survey. There was no significant difference in the distribution of age between those completing the survey and nonresponders $(p=0.30)$. However, responders were more likely to have DCIS than were nonresponders $(51.4 \%$ versus $42.1 \%, p<$ $0.05)$. The average time between diagnosis and completion of the survey was approximately 13 weeks, with information being obtained within 4 months of diagnosis from $80 \%$ of participants and within 6 months for over $90 \%$.

\section{Patient characteristics}

The mean age was 61.4 years (range 30-92 years), and $51.7 \%$ of women were currently married (Table 1). About $80 \%$ were white, and $17.3 \%$ were African American. Regarding education, $23.1 \%$ were college graduates, $32.4 \%$ had some college, $26.9 \%$ were high school graduates, and $17.6 \%$ had less than a high school education. Per our selection criteria, $49.1 \%$ (90) of women had pathology reports showing DCIS, and 51.9\% (93) had invasive disease (59 were local stage and 34 were regional stage). Women with DCIS were somewhat younger compared with those with in- 
Table 1. Characteristics of Study Sample by Stage of Disease

\begin{tabular}{lccccc}
\hline Variable & $\begin{array}{c}\text { Total sample } \\
(\mathrm{n}=183)\end{array}$ & $\begin{array}{c}\text { DCIS } \\
(\mathrm{n}=90)\end{array}$ & $\begin{array}{c}\text { Local } \\
(\mathrm{n}=59)\end{array}$ & $\begin{array}{c}\text { Regional } \\
(\mathrm{n}=34)\end{array}$ & $\mathrm{p}$ value $^{\mathrm{a}}$ \\
\hline $\begin{array}{l}\text { Age, years (mean) } \\
\text { Race (\%) }\end{array}$ & 61.4 & 59.3 & 64.1 & 62.2 & 0.08 \\
$\quad$ White & 77.1 & 77.8 & 80.7 & 68.8 & \\
$\quad$ Black & 17.3 & 17.8 & 10.5 & 28.1 & 0.10 \\
$\quad$ Other & 5.6 & 4.4 & 8.9 & 3.1 & \\
$\quad \begin{array}{l}\text { Education (\%) } \\
\quad \text { High school }\end{array}$ & 17.6 & 16.7 & 19.0 & 17.7 & \\
$\quad$ High school graduate & 26.9 & 22.2 & 31.0 & 32.3 & \\
$\quad \begin{array}{l}\text { Some college } \\
\quad \text { ollege graduate or more }\end{array}$ & 32.4 & 36.7 & 27.6 & 29.4 & \\
$\quad \begin{array}{l}\text { Marital status (\%) } \\
\quad \text { Married }\end{array}$ & 23.1 & 25.4 & 22.4 & 20.6 & \\
$\quad \begin{array}{l}\text { Surgery type (\%) } \\
\quad \text { Mastectomy }\end{array}$ & 51.7 & 54.4 & 48.3 & 50.0 & \\
$\quad$ Lumpectomy & 52.5 & 48.9 & 45.8 & 73.5 & $<0.05$ \\
\hline
\end{tabular}

${ }^{\mathrm{a}} p$ value for differences in distribution of characteristic across stage groups.

vasive disease, and the distribution of race and education was not significantly different across stage groups (Table 1). Surgery for the 183 patients was performed by 90 different attending surgeons (73 surgeons had one or two cases, 10 surgeons had 3 cases, and 7 surgeons had four or more cases).

Overall, $52.5 \%$ of the women in the sample received mastectomy (Table 1). Women with regional disease were most likely to receive mastectomy $(73.5 \%$ versus $45.8 \%$ for local disease and $48.9 \%$ for DCIS, $p<0.05)$. This was largely due to a greater likelihood of there being contraindications to BCS among women with regional disease $(38.2 \%$ versus $13.9 \%$ and $13.4 \%$ of those with local disease and DCIS, respectively, $p<0.05$ ). The rate of BCS did not differ significantly between women with DCIS and those with local disease.

\section{Role of the surgeon}

The study results suggest that surgeons played an important role in the surgery decision-making process and that this was the case across stage groups. One third of women in the sample $(n=$ 61) reported that they were not given an option between the two surgical treatments (Fig. 1). Among women who did not perceive choice, $59.9 \%(n=36)$ reported that they received a mastectomy because their surgeon told them they had a clinical contraindication to lumpectomy, such as the "lump was too big" or "multifocal disease," whereas $40.1 \%(n=25)$ of women received lumpectomy (none reported a contraindication to mastectomy). Women with regional disease were more likely to have perceived no choice $(47.1 \%$ versus $27.6 \%$ and $30.1 \%$ for women with local disease and DCIS, respectively, $p<0.01$ ), and this was largely because of a higher proportion reporting contraindications to BCS. Of the 122 women who perceived that they were given a choice between surgical treatments, $57.3 \%(n=$ 70) reported they received a recommendation from their surgeon favoring one treatment over the other $(51.6 \%, 61.5 \%$, and $62.2 \%$ of women with DCIS, local disease, and regional disease, respectively, $p=0.35$ ), of which $92.3 \%$ received the procedure recommended (which was mastectomy in about one half of the cases).

\section{Influence of patient attitudes and preferences on type of surgical treatment}

Women's' attitudes were important correlates of surgical treatment type for those who perceived a choice. Women who reported being greatly influenced by concerns about the clinical benefits and risks of the surgical procedures were more likely to have received a mastectomy than women who reported less influence by these concerns (Table 2). For example, women who were greatly concerned about "getting rid of the disease" had an adjusted OR for mastectomy of 2.6, 


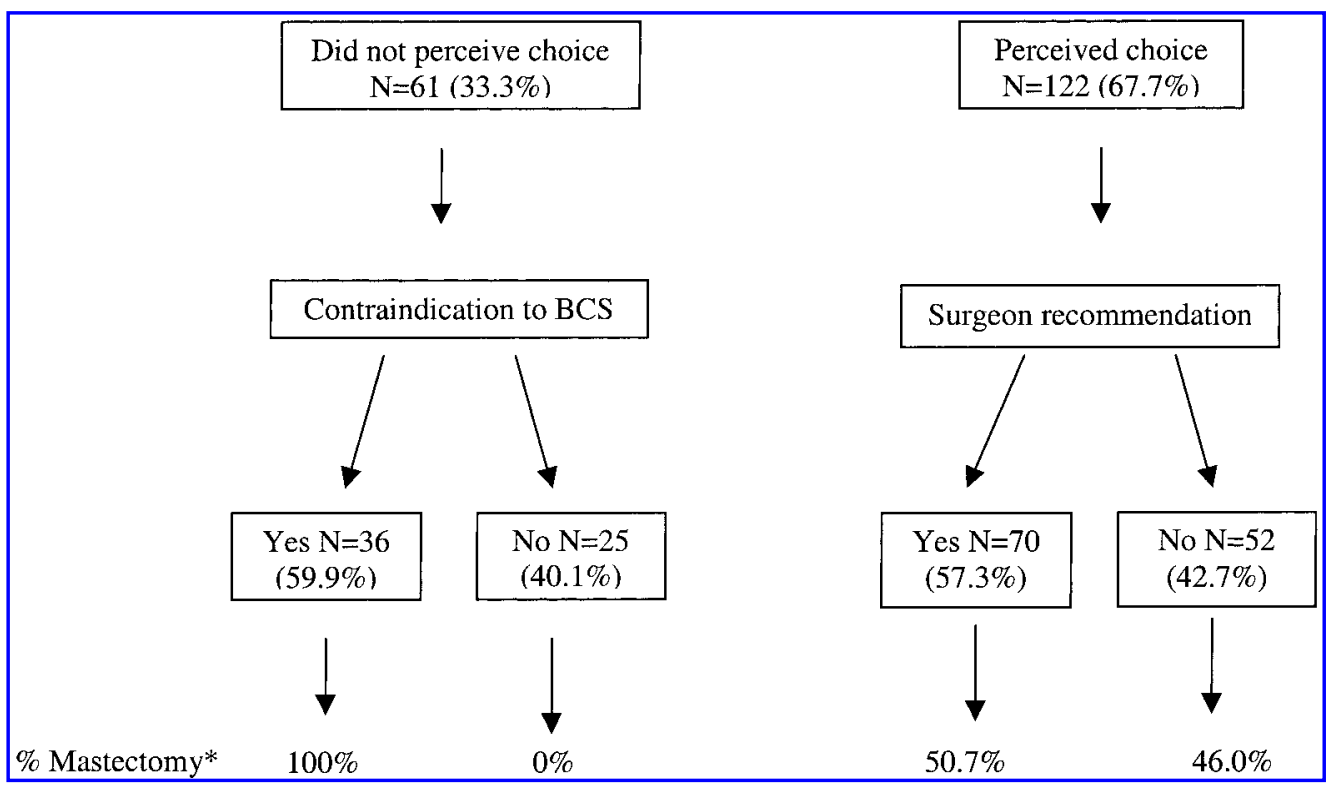

FIG. 1. Perceived choice and surgeon recommendation for surgical treatment of breast cancer. * Overall mastectomy rate for the total sample population was $52.5 \%$.

controlling for age and stage (95\% CI 1.2, 5.8). Women who were greatly influenced by the desire to reduce the need for additional surgery were also more likely to have received mastectomy (adjusted OR $=3.8,95 \%$ CI 1.7, 8.5). Thus, it appeared that women who were most concerned about the effectiveness of the surgical pro- cedures were more likely to have chosen mastectomy. These results were similar for women with and without DCIS. For instance, the OR for receipt of mastectomy for women greatly concerned about "getting rid of the disease" was 2.5 $(95 \%$ CI $0.7,7.4)$ for women with DCIS, $2.6(95 \%$ CI $0.7,5.8$ ) for women with local disease, and 3.4

Table 2. Attitudinal Factors Influencing Treatment Decisions for Women with Breast Cancer Who Perceived Choice of Surgical Options $(n=122)$

\begin{tabular}{lccc}
\hline Question item & $\begin{array}{c}\text { Greatly influenced } \\
\text { by factor }(\%)\end{array}$ & $\begin{array}{c}\text { Mastectomy } \\
(\%)\end{array}$ & OR $^{\mathrm{b}}(95 \% \mathrm{CI})$ \\
\hline Benefits and risks & & & \\
$\quad$ Get rid of disease & 62.3 & 57.9 & $2.6(1.2,5.8)$ \\
$\quad$ Reduce risk of returning & 61.7 & 58.7 & $2.6(1.1,5.8)$ \\
$\quad$ Reduce add surgery & 42.2 & 67.3 & $3.8(1.7,8.5)$ \\
$\quad$ Avoid side effects of & 23.5 & 75.9 & $4.9(1.8,13.2)$ \\
$\quad$ radiation & & & \\
Body/sexuality & 22.3 & 10.7 & $0.1(0.0,0.3)$ \\
$\quad$ Allow to keep breast & 18.2 & 45.9 & $0.7(0.3,1.9)$ \\
Feel like a women & 16.5 & 35.2 & $0.6(0.2,1.3)$ \\
$\quad$ Not feel bad about body & 6.2 & 12.4 & $0.1(0.0,0.9)$ \\
$\quad$ Not interfere with sex & 25.3 & 35.8 & $0.5(0.2,1.1)$ \\
Barriers & 18.0 & 43.8 & $0.8(0.3,1.9)$ \\
$\quad$ Quick recovery & 15.0 & 47.8 & $0.9(0.3,2.5)$ \\
Resume usual activities & 13.2 & 52.3 & $1.2(0.4,3.2)$ \\
$\quad$ Not interfere with daily life & & \\
Be convenient & & & \\
\hline
\end{tabular}
item

aPercent of women who received a mastectomy among women who reported being greatly influenced by a given

${ }^{b} \mathrm{OR}$ for having a mastectomy for women who reported being greatly influenced by a given item compared with all other women, controlling for age, stage, education, and marital status. 
(95\% CI 0.4 9.9) for women with regional disease. Interaction terms between stage and the individual attitudinal variables were not significant.

Women's concerns about body appearance and sexual functioning were also important correlates, but fewer women reported being greatly influenced by these factors than those related to clinical benefits and risks. Women who reported being greatly concerned about these factors appeared to favor lumpectomy (Table 2). For example, women who reported being greatly influenced by concerns that the procedure should "not interfere with long-term sexual functioning" $(6.2 \%)$ were much less likely to have received a mastectomy (adjusted OR $=0.1,95 \%$ CI 0.1, 0.9). Again, these findings did not vary by stage of disease at diagnosis. For example, the OR for mastectomy for women who were greatly influenced by concerns that treatment should "allow you to keep your breast" was 0.08 for women with DCIS (95\% CI 0.01, 0.7) and 0.12 for women with invasive disease $(95 \%$ CI $0.03,0.32)$.

Finally, some women reported that concerns about certain aspects of treatment greatly influenced their surgery choice, although the number of women reporting these concerns was generally less than those for concerns associated with clinical benefits and risks. The barriers reported included being concerned about having a quick recovery $(25.3 \%)$, being able to resume usual activities $(18.0 \%)$, not having the treatment interfere with daily life $(15.0 \%)$, and the treatment's being convenient $(13.2 \%)$. None of these factors, however, were significantly associated with the type of surgical treatment received (Table 2). The patterns in the results were similar for women with DCIS and those with invasive disease. For example, $29.4 \%$ of women with DCIS, $25.0 \%$ of women with local disease and $20.2 \%$ of women with regional disease reported being highly concerned about having a quick recovery from treatment $(p=0.44)$.

\section{Patient knowledge about clinical benefits and risks of treatment options}

In general, respondents' knowledge about differences in the clinical benefits and risks of mastectomy versus lumpectomy with radiation was low (Table 3). Only about one third of women with DCIS and invasive disease who perceived choice of surgical treatments believed that survival was the same for both procedures. Nearly half of the women did not know whether the chance of recurrence was different between the two procedures, and one third of women with DCIS and one quarter of those with invasive disease reported that the chances of recurrence were the same. Differences in item responses by stage of disease were not statistically significant. Knowledge of the risks and benefits of the procedures, however, was associated with surgical treatment type. Women who perceived that survival was the same between the two procedures were more likely to choose lumpectomy compared with all other women (OR for lumpectomy controlling for age and stage was 2.1, 95\% CI 1.1, $4.0)$.

\section{Patient satisfaction}

Among women who perceived choice, satisfaction with the treatment decision they made (as measured with the Holmes-Rovner scale) was not associated with age $(p=0.26)$, education ( $p=$ $0.31)$, stage of disease $(p=0.97)$, or treatment choice $(p=0.77)$. However, the survey results

Table 3. Knowledge about Differences in Risks and Benefits of Surgery Options for Women with Breast Cancer $(n=122)$

\begin{tabular}{|c|c|c|c|c|c|c|}
\hline \multirow[b]{2}{*}{ Knowledge item } & \multirow{2}{*}{$\begin{array}{c}\% \\
\text { Correct }\end{array}$} & \multicolumn{2}{|c|}{ DCIS $(\mathrm{n}=64)$} & \multirow{2}{*}{$\begin{array}{c}\% \\
\text { Correct }\end{array}$} & \multicolumn{2}{|c|}{ Invasive $(\mathrm{n}=58)$} \\
\hline & & Incorrect & Don't know & & Incorrect & Don't know \\
\hline $\begin{array}{l}\text { Survival for lumpectomy with radiation } \\
\text { is the same as it is for a mastectomy. }\end{array}$ & 31.2 & 28.2 & 40.6 & 36.2 & 13.8 & 50.0 \\
\hline $\begin{array}{l}\text { Radiation is usually necessary after } \\
\text { lumpectomy. }\end{array}$ & 78.0 & 1.7 & 20.3 & 67.2 & 6.9 & 25.9 \\
\hline $\begin{array}{l}\text { The chances that breast disease will come } \\
\text { back after surgery are the same for } \\
\text { mastectomy as they are for lumpectomy. }\end{array}$ & 20.3 & 35.9 & 43.8 & 31.0 & 22.4 & 46.6 \\
\hline
\end{tabular}

a Differences in item responses by stage of disease were not statistically significant. 
suggested that women who did not perceive they were given surgical treatment choice were less satisfied with the decision-making process than those who perceived they had a choice. Table 4 shows responses to questions about satisfaction with the decision-making process for the entire sample stratified by stage and perception of treatment choice. Compared with women who perceived choice, many more women who did not perceive choice would have liked to have been more active in making the decision $(46.0 \%$ versus $10.0 \%$ for DCIS, $28.6 \%$ versus $8.0 \%$ for invasive disease), did not have as much to say about what kind of surgery to have as they wanted $(37.5 \%$ versus $13.3 \%$ for DCIS, $32.1 \%$ versus $8.1 \%$ for invasive disease), and felt that they had less control in the decision-making process than they would have liked (31.3\% versus $6.6 \%$ for DCIS, $35.7 \%$ versus $4.8 \%$ for invasive disease). These large differences in satisfaction between women who did not perceive choice and those that did perceive choice were statistically significant $(p<0.01)$ and consistent across stage of disease.

\section{DISCUSSION}

In this population-based study, we found that women reported a number of factors that influenced decisions about surgical treatment for breast cancer. These factors were largely consistent across stage of disease. Women with regional disease had a higher rate of mastectomy, but this was largely the result of more clinical contraindications to BCS. There were no substantial differences between women with DCIS and those with invasive disease in regard to their knowl- edge or attitudes about surgical treatment options or in patient satisfaction with the decisionmaking process. This suggests that many factors that both surgeons and patients took into account when considering surgical treatment alternatives did not significantly vary between women with DCIS and those with invasive breast cancer, including local disease.

Surgeons appeared to have an important influence on surgical treatment decisions. One third of women in our sample did not perceive they were given a choice; over half of these women reported that they received a mastectomy because of a clinical contraindication to lumpectomy. However, the rest of these women (about $14 \%$ of the total sample) reported that they were told that they had to receive a lumpectomy, none of whom reported any contraindications to mastectomy. Among women who perceived surgical choice yet also received a recommendation from a surgeon, the vast majority followed that recommendation.

Patient attitudinal factors were important correlates of treatment type. In particular, many women reported that they were greatly concerned about clinical benefits and risks, and these factors were significantly associated with receipt of mastectomy. A much smaller proportion of women reported being greatly influenced by body image or sexuality factors. Consistent with previous studies, body image and sexuality concerns tended to be associated with receipt of lumpectomy. ${ }^{7,39,40}$

Many women in this study, including those with DCIS, appeared to view mastectomy as a more definitive treatment for breast cancer. Studies have shown that women with DCIS do face

Table 4. Satisfaction with Decision-Making Process $(n=183)$

\begin{tabular}{lccccc}
\hline & \multicolumn{2}{c}{ DCIS $(\mathrm{n}=90)$} & & \multicolumn{2}{c}{ Invasive $(\mathrm{n}=93)$} \\
\cline { 2 - 3 } \cline { 5 - 6 } Item & $\begin{array}{c}\text { No choice } \\
(\mathrm{n}=28)\end{array}$ & $\begin{array}{c}\text { Choice } \\
(\mathrm{n}=62)\end{array}$ & $\begin{array}{c}\text { No choice } \\
(\mathrm{n}=32)\end{array}$ & $\begin{array}{c}\text { Choice } \\
(\mathrm{n}=61)\end{array}$ \\
\hline $\begin{array}{l}\text { Would liked to have been more active in } \\
\text { making the decision about what kind of } \\
\text { surgery to have }\end{array}$ & $46.0 \%$ & $10.0 \%$ & $28.6 \%$ & $8.0 \%$ \\
$\begin{array}{c}\text { Did not have as much to say about what } \\
\text { kind of surgery to have as I wanted }\end{array}$ & $37.5 \%$ & $13.3 \%$ & $32.1 \%$ & $8.1 \%$ \\
$\begin{array}{l}\text { Did not have enough control in making } \\
\text { the surgery treatment decision }\end{array}$ & $31.3 \%$ & $6.6 \%$ & $35.7 \%$ & $4.8 \%$ \\
\hline
\end{tabular}

${ }^{a}$ Differences between patients who did not perceive choice compared with those who did perceive choice were significant within each stage category, $p<0.01$. 
the risk of recurrence and that many of these cancers will be invasive. ${ }^{20,22,23}$ Thus, patient concerns about differences in effectiveness of surgical treatments likely reflected legitimate concerns about differences in the rate of local recurrence based on the available information. However, the low level of patient knowledge about the clinical benefits and risks of the two procedures suggested that some of the perceptions patients had about the procedures may not have been based on accurate information. For instance, our results suggested that the favorable view of mastectomy held by some women appeared to extend to survival and that this may have influenced women's choice of procedure. In regard to local recurrence, it appears likely that some women were not fully aware of important differences between the procedures. These results were found in a state that has legislated that all breast cancer patients receive information on treatment options at the time of diagnosis. ${ }^{41}$

Our results regarding patient satisfaction reinforce the notion that the decision-making process may be as important as the actual procedure chosen. Consistent with previous studies, our results suggest that breast cancer patients are more dissatisfied when they do not achieve the level of participation in the treatment decision-making process that they desire. ${ }^{38,42-44}$ These findings suggest that the way that women with breast cancer and their surgeons communicate about treatment options may be as important a correlate of subsequent patient satisfaction as the actual treatment chosen and that there is a need to better assess and accommodate patient's preferences for participation in the decision-making process. ${ }^{45}$

Several aspects of the study merit comment. Although our study sample was from a population-based tumor registry, the sample size was not adequate to perform extensive multivariate analyses to assess all independent associations with treatment and all potential sources of confounding. Furthermore, the target population was one SEER catchment area in the Midwest. The rapid case-reporting process we used in this study missed $<20 \%$ of incident cases in the region because smaller hospitals do not participate. Thus, our findings may not be generalizable to patients from other regions of the country, in particular those from smaller hospitals or living in rural areas. In addition, our results may reflect some recall bias because we assessed patient perspectives about their treatment experience retro- spectively after surgery. For instance, patient perceptions about satisfaction with the decisionmaking process may be biased by current health status, quality of life, or experiences that occurred after the surgery. Finally, response bias also may have influenced our results, although our response rate was typical for survey research efforts, and there were few differences in key characteristics between responders and nonresponders.

Clinicians face special challenges when communicating with patients about treatment options for serious illnesses. Our results suggest a number of important correlates of surgical treatment choice that may help providers better understand patient perceptions of these treatment issues. One important challenge for clinicians is understanding patient preferences for participation in medical decision making. A growing literature suggests that patient preferences for participation in medical decision making vary substantially, especially in the midst of a medical crisis. ${ }^{46}$ Our results suggest that the process of communication and decision making may be as important to patients as the actual treatment chosen. Thus, more research will be required to better understand how the process of decision making affects outcomes, such as patient satisfaction and health-related quality of life.

\section{ACKNOWLEDGMENTS}

We thank Linda Weiss, Ph.D., and Kendra Schwartz, M.D., for research design and data collection support.

\section{REFERENCES}

1. National Institutes of Health. NIH Consensus Development Conference Statement. The treatment of early stage breast cancer. 1990.

2. Yurek D, Farrar W, Andersen B. Breast cancer surgery: Comparing surgical groups and determining individual differences in postoperative sexuality and body change stress. J Consult Clin Psychol 2000;68: 697.

3. Fisher B, Anderson S, Redmond CK, Wolmark N, Wickerham DL, Cronin WM. Reanalysis and results after 12 years of follow-up in a randomized clinical trial comparing total mastectomy with lumpectomy with or without irradiation in the treatment of breast cancer. N Engl J Med 1995;333:1456. 
4. Miller PJ. Mastectomy: A review of psychosocial literature. Health Soc Work 1981;6:60.

5. Levy SM, Herberman RB, Lee JK, et al. Breast conservation versus mastectomy: Distress sequelae as a function of choice. J Clin Oncol 1989;7:367.

6. Margolis GJ, Goodman RL, Rubin A, et al. Psychological factors in the choice of treatment for breast cancer. Psychosomatics 1989;30:192.

7. Moyer A. Psychosocial outcomes of breast-conserving surgery versus mastectomy: A meta-analytic review. Health Psychol 1997;16:284.

8. Farrow DC, Hunt WC, Samet JM. Geographic variation in the treatment of localized breast cancer. $\mathrm{N} \mathrm{Engl}$ J Med 1992;326:1097.

9. Lazovich D, White E, Thomas DB, et al. Underutilization of breast-conserving surgery and radiation therapy among women with stage I and II breast cancer. IAMA 1991;266:3433.

10. Lazovich D, Solomon CC, Thomas DB, et al. Breast conservation therapy in the United States following the 1990 National Institutes of Health Consensus Development Conference on the Treatment of Patients with Early Stage Invasive Breast Carcinoma. $\underline{\text { Cancer }}$ 1999;86:628.

11. Nattinger AB, Gottlieb MS, Veum J, Yahnke D, Goodwin JS. Georgraphic variation in the use of breast-conserving treatment for breast cancer. $\mathrm{N}$ Engl J Med 1992;326:1102.

12. Nattinger $A B$, Hoffman RG, Shapiro R, Gottlieb MS, Goodwin JS. The effect of legislative requirements on the use of breast-conserving surgery. $\mathrm{N}$ Engl J Med 1996;335:1035.

13. Michalski TA, Nattinger AB. The influence of black race and socioeconomic status on the use of breastconserving surgery for Medicare beneficiaries. Cancer 1997;79:314.

14. Mandelblatt J, Hadley J, Kerner J, et al. Patterns of breast carcinoma treatment in older women: Patient preferences and clinical and physical influences. Cancer 2000;89:561.

15. Morris C, Cohen R, Schlag R, Wright W. Increasing trends in the use of breast-conserving surgery in California. Am J Public Health 2000;90:281.

16. Dolan J, Granchi T, Miller C, Brunicardi F. Low use of breast conservation surgery in medically indigent populations. Am J Surg 1999;178:470.

17. Adams-Cameron M, Gilliland F, Hunt W, Key C. Trends in incidence and treatment for ductal carcinoma in situ in Hispanic, American Indian, and nonHispanic white women in New Mexico, 1973-1994. Cancer 1999;85:1084.

18. Millikan R, Dressler L, Geradts J, et al. The need for epidemiologic studies of in situ carcinoma of the breast. Breast Cancer Res Treat 1995;35:65.

19. Landis SH, Murray T, Bolden S, et al. Cancer statistics, 1998. CA 1998;48:6.

20. Silverstein MJ. Fortnightly review: Ductal carcinoma in situ of the breast. Br Med J 1998;317:734.

21. van Dongen JA, Holland R, Peterse JL, et al. Ductal carcinoma in situ of the breast: Second EORTC consensus meeting. Eur J Cancer 1992;28:626.
22. Silverstein MJ, Barth A, Poller DN, et al. Ten-year results comparing mastectomy to excision and radiation therapy for ductal carcinoma in situ of the breast. Eur J Cancer 1995;31A:1425.

23. White J, Levine A, Gustafson G, et al. Outcome and prognostic factors for local recurrence in mammographically detected ductal carcinoma in situ of the breast treated with conservative surgery and radiation therapy. Int J Radiat Oncol Biol Phys 1995;31:791.

24. Ernster VL, Barclay J, Kerlikowske, et al. Incidence of and treatment of ductal carcinoma in situ of the breast. JAMA 1996;275:913.

25. Winchester DP, Menck HR, Osteen RT, et al. Treatment trends for ductal carcinoma in situ of the breast. Ann Surg Oncol 1995;2:207.

26. Carty NJ, Carter C, Royle GT, et al. Management of ductal carcinoma in situ of the breast. Ann R Coll Surg Engl 1995;77:163.

27. Coleman EA, Kessler LG, Wun LM, et al. Trends in the surgical treatment of ductal carcinoma in situ of the breast. Am J Surg 1992;164:74.

28. Whelan T, Levine M, Gafni A, et al. Mastectomy or lumpectomy? Helping women make informed choices. J Clin Oncol 1999;17:1727.

29. Stanton A, Estes M, Estes N, Cameron C, Danoff-Burg $S$, Irving L. Treatment decision making and adjustment to breast cancer: A longitudinal study. I Consult Clin Psychol 1998;66:313.

30. Lazovich D, Raab K, Gurney J, Chen H. Knowledge and preference for breast conservation therapy among women without breast cancer. Women's Health Iss 2000;10:210.

31. Graling PR, Grant JM. Demographics and patient treatment choice in stage I breast cancer. AORN J 1995; 62:376.

32. Satariano ER, Swanson GM, Moll PP. Nonclinical factors associated with surgery received for treatment of early-stage breast cancer. Am J Public Health 1992;82: 195.

33. Anema MG, Brown BE. Increasing survey responses using the total design method. J Contin Educ Nurs 1995;26:109.

34. Janz NK, Becker MH. The Health Belief Model: A decade later. Health Edu Q 1984;11:1.

35. Bandura A. Social foundations of thought and action. Englewood Cliffs, NJ: Prentice-Hall, 1986.

36. Andersen RM, McCutcheon A, Aday LA, et al. Exploring dimensions of access to medical care. Health Serv Res 1983;1811:49.

37. Holmes-Rovner M, Kroll J, Schmitt N, et al. Patient satisfaction with health care decisions: The Satisfaction with Decision Scale. Med Decis Making 1996; 16:58.

38. Pierce PF. Deciding on breast cancer treatment: A description of decision behavior. Nurs Res 1993;42:22.

39. Ward S, Heidrick S, Wolberg W. Factors women take into account when deciding upon type of surgery for breast cancer. Cancer Nurs 1989;12:344.

40. Stafford D, Szczys R, Becker R, et al. How breast cancer treatment decisions are made by women in North Dakota. Am J Surg 1998;176:515. 
41. Nayfield SG, Bongiovanni GC, Alciati MH, et al. Statuatory requirements for disclosure of breast cancer treatment alternatives. I Natl Cancer Inst 1994;86: 1202.

42. Degner LF, Krisjanson LJ, Bowman D, et al. Information needs and decisional preferences in women with breast cancer. JAMA 1997;277:1485.

43. Bilodeau BA, Degner LF. Information needs, sources of information, and decisional roles in women with breast cancer. Oncol Nurs Forum 1996;23:691.

44. Gafni A, Charles C, Whelan T. The physician-patient encounter: The physician as a perfect agent for the patient versus the informed treatment decision-making model. Soc Sci Med 1998;47:347.

45. Lantz P, Zemencuk J, Katz S. Is mastectomy over-uti- lized? A call for a new perspective. Health Serv Res In press.

46. Schneider CE. From consumer choice to consumer welfare. Hastings Cent Rep 1995(Special Supplement):S25.

\author{
Address reprint requests to: \\ Steven J. Katz, M.D., M.P.H. \\ Department of Internal Medicine \\ University of Michigan \\ 3116 Taubman Center \\ Ann Arbor, MI 48109-0376
}

\section{APPENDIX}

\section{Preamble and question formats for the patient attitudinal factors}

Women who need breast surgery think about many things when they are trying to decide whether to have a mastectomy or lumpectomy. We are interested in how much each of the following things influenced your decision. Please try to remember as best you can the number that most closely matches your answer for each item. Please take your time.

When you were deciding between mastectomy and lumpectomy, how much was your decision influenced by whether the treatment you chose:

Benefits and risks

Would get rid of the disease

Would reduce the chances the disease would come back

Would reduce the possibility of having additional surgeries

Would help you avoid the side effects of radiation

\section{Body/sexuality}

Would allow you to keep your breast

Would allow you to still feel like a woman

Would not make you feel bad about your body

Would not interfere with your sex life in the long term

\section{Barriers}

Would allow you to recover quickly

Would allow you to resume your usual activities

Would not be disruptive to your life

Would be convenient to get

\section{Holmes-Rovner satisfaction with treatment decision scale (Cronbach alpha 0.88)}

I am satisfied that I was adequately informed about the issues important to the decision about what kind of surgery to have.

The decision made about surgery was the best decision possible for me personally. 
I am satisfied that the decision about surgery was consistent with my personal values.

I am satisfied that I successfully carried out the decision about what type of surgery to have.

I am satisfied that this was my decision to make.

I am satisfied with the decision about what kind of surgery to have.

\section{Items for satisfaction with surgical treatment decision-making process}

I would like to have been more active in making the decision about what kind of surgery to have. I did not have as much to say about what kind of surgery to have as I wanted.

I believe that I had enough control in making the surgical treatment decision. 


\section{This article has been cited by:}

1. Shahla Masood. 2008. Significance of patient education and counseling in improving breast healthcare. Women's Health 4:6, 551-555. [CrossRef]

2. Judy Y. Chen, May L. Tao, Diana Tisnado, Jennifer Malin, Clifford Ko, Martha Timmer, John L. Adams, Patricia A. Ganz, Katherine L. Kahn. 2008. Impact of Physician-Patient Discussions on Patient Satisfaction. Medical Care 46:11, 1157-1162. [CrossRef]

3. Judy Y. Chen, Allison L. Diamant, Amardeep Thind, Rose C. Maly. 2008. Determinants of breast cancer knowledge among newly diagnosed, low-income, medically underserved women with breast cancer. Cancer 112:5, 1153-1161. [CrossRef]

4. Sarah T. Hawley, Tim P. Hofer, Nancy K. Janz, Angela Fagerlin, Kendra Schwartz, Lihua Liu, Dennis Deapen, Monica Morrow, Steven J. Katz. 2006. Correlates of Between-Surgeon Variation in Breast Cancer Treatments. Medical Care 44:7, 609-616. [CrossRef]

5. Rose C. Maly, Yoshiko Umezawa, Carl T. Ratliff, Barbara Leake. 2006. Racial/ethnic group differences in treatment decision-making and treatment received among older breast carcinoma patients. Cancer 106:4, 957-965. [CrossRef]

6. M Schaapveld, E G E de Vries, R Otter, J de Vries, W V Dolsma, P H B Willemse. 2005. Guideline adherence for early breast cancer before and after introduction of the sentinel node biopsy. British Journal of Cancer 93:5, 520-528. [CrossRef]

7. Paula M. Lantz, Nancy K. Janz, Angela Fagerlin, Kendra Schwartz, Lihua Liu, Indu Lakhani, Barbara Salem, Steven J. Katz. 2005. Satisfaction with Surgery Outcomes and the Decision Process in a Population-Based Sample of Women with Breast Cancer. Health Services Research 40:3, 745-768. [CrossRef]

8. Wendy WT Lam, Richard Fielding, Ella YY Ho, Miranda Chan, Amy Or. 2005. Surgeon's recommendation, perceived operative efficacy and age dictate treatment choice by Chinese women facing breast cancer surgery. Psycho-Oncology 14:7, 585. [CrossRef]

9. Shahla Masood. 2003. Why Most Women With Breast Cancer Still Undergo Mastectomy. The Breast Journal 9:2, 69-70. [CrossRef]

10. Paula M. Lantz, Judith K. Zemencuk, Steven J. Katz. 2002. Is Mastectomy Overused? A Call for an Expanded Research Agenda. Health Services Research 37:2, 417-431. [CrossRef] 